\title{
The communication channels in fostering energy conservation behaviour
}

\author{
Mastura $^{\mathrm{a}}$, Low Sheau-Ting ${ }^{\mathrm{b}, *}$ \\ ${ }^{a}$ Department of Real Estate, Faculty of Geoinformation and Real Estate, Universiti Teknologi Malaysia, Skudai, 81310 Johor, \\ Malaysia \\ ${ }^{b}$ Centre of Real Estate Studies, Institute for Smart Infrastructures and Innovative Construction, Universiti Teknologi Malaysia, \\ Skudai, 81310 Johor, Malaysia
}

\begin{abstract}
In Malaysia, the total energy consumption is high particularly in commercial sector. The building's energy demand is among the main contributors to the country's energy use. National Energy Balance 2012 stated that commercial sector is the second higher which contributed $33.2 \%$ of energy usage after industry $45.1 \%$ and followed by residential sector of $21.2 \%$. One of the major challenges faced by facilities manager is to reduce the building's energy consumption. Although there are previous energy conservation programs launched, the energy conservation progress in building still lacking behind. To improve building user's energy conservation behaviour effectively, selection of right communication channels then distributes energy conservation messages with the right communication channels remains an important strategy. Critical literature search found that there are six types of communication channels are appropriate to be used to foster energy conservation behaviour: dialogue oriented approach, mass media, print media, outdoor media, audio visual media and utility items.
\end{abstract}

Keywords: Energy conservation behavior, communication channel

\section{Introduction}

In this modern era, it is easy to obtain and access information from various sources globally. Information in the form of messages is conveyed through the medium called communication channels. This study aims to identify the communication channels to foster energy conservation behaviour. Various energy challenges poses treats to the world to achieve a sustainable energy future. These challenges include depleted energy resources, the increase of world temperature, rising of sea levels, and environmental degradation. One of the immediate solutions is to reduce the energy demand. The issue of global warming issues nowadays that caused by excessive energy usage is one of the proofs that world is negatively affectedly by human activities. The Earth Hour Day which was held on the 29th March 2014 from $8.30 \mathrm{pm}$ to $9.30 \mathrm{pm}$ proved that energy conservation behaviour is still needed to reduce the impact of global warming [1]. According to [2] "programs that intend to foster sustainable behaviour should include a communication component". Appropriate communication channel is among the keys to ensure effective information delivery. According to [3], energy is one of the crucial elements for a sustainable development. This means that in order to achieve a sustainable development, we have to sustain our energy sources which is depleting from day to day. Globally, buildings are set up for business related competition, not realizing the tremendous energy wasted. According to [4], China's industrial energy consumption increased by $134 \%$ from 1996 to 2010 although the economic energy intensity decreased by $46 \%$. For the case in the United Kingdom, the country's total energy consumption in 2013 has increased $0.7 \%$ in compared to the previous year [5]. According to [3], Malaysian are one of the largest electricity

\footnotetext{
*Manuscript received May 15, 2015; revised September 15, 2015.

Corresponding author. Tel.: 016-7186819; E-mail address: sheauting@utm.my

doi: $10.12720 /$ sgce.4.4.361-364
} 
consumers among the people of the Southeast Asian Nations member countries. The demands of energy are expected to increase due to social development and economic growth. These ongoing developments are parallel with the increases in the demand for energy.

According to [6], people do know about global warming but society is not ready to move ahead where they still use electricity like never been reminded. The nation need to practice energy conservation behaviour not only for reducing cost of electricity but also for saving the depleting world's natural resources. Proper end user energy management can save 20 percent of the building electricity consumption [7]. According to [8], people need tools for the voluntary behavioural changes, in which some of the tools includes various communication channels such as word of mouth, using prompts, using groups, using media for reminders and many other tools. Thus, in order to improve users' energy conservation behaviour, the selection of right communication channels remains as an important strategy. A manager will face many alternative channels to use and due to this, appropriate and relevant choices must be made so that this contributes to the effectiveness of solution [9]. Selecting inappropriate communication channels might contribute to program failure.

There are many studies carried out which uses a variety of communication channels to effectively raise awareness and change people's behaviour. One of the examples is using video a channel to raise awareness and communicate the information on climate change and global warming. According to [10], there is one environmental video with the title "The Most Terrifying Video You'll Ever See" and "An Inconvenient Truth" that reached million viewers which is proven successful in raising energy awareness among people. Other study by [11] has used Short Message Service (SMS) to achieve its goal to be as a reminder to change the unhealthy behaviour among people. Based on another study, it was reported that using variety of communication channels in marketing has improved the hygiene behaviour of 497 women in Ghana [12]. The study showed that television and radio channels bring greater impacts than other channels on changing the behaviour with 30 percent increase in hand washing behaviour. Study by [13] has established a website www.LoseYourExcusell to educate energy efficient habit among kids. Then, for the second campaign, cartoon such as TinkerBell, Malcolm and April were used as advertisement in television and radio programme. Later, another website called www.energy.gov/tink' was established to drive kids in energy conservation behaviour. TinkerBell Cartoon was the most viewed by kids followed by others advertisement. In another study by [14], communication channels of group meeting is selected to establish "List of Conservation Actions" for energy conservation behaviour among staff and electronic mail was used to spread the energy conservation message among the building's users.

\section{Types of Communication Channels}

There are many types of communication channels that can be used for energy conservation behaviour. Some of the channels use group mouth to mouth communication which involves dialogue oriented approach. Mass communication involve any mas media or information technology while small media involve print media, outdoor media, audio visual media and utility items. The followings details the types of communication channels to foster energy conservation behavior.

\subsection{Dialogue oriented approach}

These types of channels overcome the difficulties of people accessing the media. According to Manual of Aids [15], this type of communication allows people to ask questions directly related to their own context. These dialogue oriented approach needs responsiveness from people. According to [16], dialogue is not effective until they commit themselves to the process. This means messages can successfully be delivered when people respond and fully commit to the process. The audience may have a positive or negative view regarding the topic. According to [17], a speaker needs to determine audience attitudes, beliefs and values before starting his topic. This is to make sure that audience respond suitably to the topic that will be discussed. It is important that content of the messages must be related with issues and topic to be delivered effectively to audience. People that go through the process of dialogue oriented 
approach channel may increase their level of self-awareness [18]. This also means that this communication channel will influence their attitude and behavior either by positive or negative feedback. According to [19], the dialogue oriented approach cost is based on the size and number of target groups. The cost can get bigger when the number of target group is bigger. Furthermore, there are also other communication channel used to support the dialogue oriented approach such as print media, utility items and many others. There are many examples of dialogues oriented approaches such as events, campaign, workshop, groups, folk media, counseling, lecture talk and many others.

\subsection{Mass media}

Media serve as an important source of information which includes wide range of topics [20]. This means that the media plays a big role in providing information to people. Messages content in mass media communication can be private and public depending on its circumstances. Example of public message is television and many others while private message is mobile phone and many others [21]. However, there are also effects of using mass media. One of the effects is related with socialization. Socialization is the ways of individuals adopting the behaviour of the group [20]. Socialization process involves various people and organizations. This people called agencies of socialization\| where they can influence people in different beliefs. Examples of agencies of socialization are personal experiences, school, friends, mass media, siblings and parents. According to [20], channels can be an influential force for users. Media channels can influence someone beliefs, attitude and perceptions. Thus, it is important to select the right media for energy conservation. The cost of mass media is based on the types used. Some of mass media involves high cost such as advertising on television but some of the mass media does not involve high cost such as electronic mail [22]. There are many examples of mass media such as television and radio, electronic mail, world wide web, blog, short message services, internet and online social media.

\subsection{Small media}

Small media in the context of building includes print media, audio visual media, utility items and outdoor media. Small media are useful for better understanding for people in which its support dialogue and activities such as leaflets are given during events [15]. This type of channel considers the content of message where it must have a clear and simple explanation. According to [15], the message must be clear, easy to understand and can be interpreted faster by people. This is to avoid receivers from responding differently to the message. According to [15], some of small media is not only known as low cost but also involves simpler technology whereby the leader have the greater control over the message and content. The cost involved is based on the quantity of small media used. There are few types of channels categorize as small media: print media, outdoor media, audio visual media, and utility media. The following paragraphs details each of the channel. Print media are easy and have low cost to be applied. The technology necessary to print is simple whereby ink is pressed onto the paper [21]. Small media includes print media such as sticker, posters, flyer feedback, logos and slogans and others. Other examples of small media are outdoor media. Examples of outdoor media are billboard, signage, taxis and busses and trains. Others can be ads on airplanes, phone booth, hot balloons, building and so on. It works by providing simple and strong messages [15]. Outdoor advertising or ads can be a way for people that are not familiar with mass media [23]. Cost for outdoor media cost can be expensive and also less expensive depending on the medium and size that organization used. Another types of small media is known as Audio Visual Media. This types of media including Recorded Tapes, Slides, and Displays are best suited to situations where people hear or view the displays. This channel can be used to remind people in organizations of their energy conservation behaviour. Other examples of audio visual media are CDs, video programme, signs, slides and others [15]. Lastly, Utility Media or known as utility items provides opportunities for repetitive message by the user or wearer [15]. These utility items can be distributed to the target audience with the cost depending on the total of item quantity. Examples of utility items are T-shirts, pens, rulers, caps, badges and others. 


\section{Conclusion}

In essence, there are various communication channels have been used to foster energy conservation behaviour among the building's users. These including dialogue oriented approach, mass media, print media, outdoor media, audio visual media, and utility items. The management should consider to blend various communication channels in designing energy conservation program instead of using single channel to achieve desired behaviour change. Further study can be conducted to identify the optimum combination of communication channels to foster energy conservation behaviour across various local context.

\section{Acknowledgements}

This work was financed by Fundamental Research Grant Scheme with Vote No. R.J130000.7809.4F506 provided by Ministry of Higher Education of Malaysia and Universiti Teknologi Malaysia. We also appreciate the anonymous referees for their constructive comments.

\section{References}

[1] Lights Out. The Sun. Mar 28, 2014:32.

[2] Unnisa SA, Rav SB. Eds. Sustainable Solid Waste Management. CRC Press; 2012.

[3] Ahmad S, Tahar RM. Selection of renewable energy sources for sustainable development of electricity generation system using analytic hierarchy process: a case of Malaysia. Renewable Energy, 2014; 63:458-466.

[4] Ke J, Price L, Ohshita S, Fridley D, Khanna NZ, Zhou N, Levine M. China's industrial energy consumption trends and impacts of the top- 1000 enterprises energy-saving program and the ten key energy-saving projects. Energy Policy, 2012; 50:562-569.

[5] Energy trends. United Kingdom Government report. Department of Energy and Climate Change, 2013.

[6] The Environics Institute. Canadian Public Opinion About Climate Change. Canada, 2013.

[7] Junnila S. The potential effect of end-users on energy conservation in office buildings. Facilities, 2007; 25(7-8):329-339.

[8] Ampt E. Voluntary household travel behaviour change - theory and practice. In: Proc. 10th International Conference on Travel Behaviour Research. Lucerne, 2003:1-20.

[9] Melcher AJ, Beller R. Toward a theory of organization communication: consideration in channel selection. Journal of Business Communication, 1968; 5(2):5-21.

[10] Kritmanorote K. Effective Environmental communication in the mostterrifying video you'll ever see and a inconvenient truth. Master. Hawaii Pacific University. United States, 2011.

[11] Fjeldsoe BS, Marshall AL, Miller YD. Behaviour change interventions delivered by mobile telephone short-message service. American Journal of Preventive Medicine, 2009: 36(2):165-173.

[12] Scott BE, Schmidt WP, Aunger R, Garbrah-Aidoo N, Animashaun R. Marketing hygiene behaviours: the impact of different communication channels on reported handwashing behaviour of women in Ghana. Health Education Research, 2008; 23(3):392-401.

[13] Bertrand JT, Goldman P, Zhivan N, Agyeman Y, Barber E. Evaluation of the "Lose Your Excuse" public service advertising campaign for tweens to save energy. Evaluation Review, 2011.

[14] Hargreaves T. Practice-ing behaviour change: applying social practice theory to pro-environmental behaviour change. Journal of Consumer Culture, 2011; 11(1):79-99.

[15] Parker W, Dalrymple L, Durden E. Communicating beyond aids awareness. A manual, 1998.

[16] Papa MJ, Singhal A. How entertainment-education programmes promote dialogue in support of social change. Journal of Creative Communications, 2009; 4(3):185-208.

[17] Duck S, McMahan DT. The Basics of Communication: A Relational Perspective. California: SAGE Publications Inc; 2009.

[18] Joseph DA. Human Communication. 6th edition. New York: HarperCollins College; 1994.

[19] Mikkonen I, Gynther L, Hamekoski K, Mustonen S, Silvonen S. Innovative communication campaign packages on energy efficiency. World Energy Council, ADEME, Motiva, 2010.

[20] Dominick JR. The Dynamic of Mass Communication. 12th edition. New York: McGraw-Hill Inc; 2013.

[21] Dominick JR. The Dynamic of Mass Communication. 4th edition. New York: McGraw-Hill Inc; 1998.

[22] Black J. Introduction to Media Communication. 4th edition. Dubuque: Brown and Benchmark; 1995.

[23] Yin S. Counting eyes on billboards. American Demographics, 2002:24-27. 